\title{
İş Stresinin Algılanan Yönetici Desteği İle İşten Ayrılma Niyeti Arasındaki İlişkide Üstlendiği Rol ${ }^{1}$
}

DOI: $10.26466 /$ opus.662681

\begin{abstract}
*
Aynur Taș ${ }^{*}$ Zülfi Umut Özkara**

* Dr. Öğr. Üyesi, Hakkari Üniversitesi, İ.I.B.F, İşletme Bölümü, Hakkari/Türkiye E-Posta: aynurtas@hakkari.edu.tr ORCID: $\underline{0000-0001-6810-8358}$

** Öğr. Gör. Dr., Ankara Hacı Bayram Veli Üni., Ban. ve Sig. Y. O, Bankacılık Böl., Ankara/Türkiye E-Posta: umut.ozkara@hbv.edu.tr ORCID: 0000-0002-5031-808X

\section{Öz}

$\mathrm{Bu}$ çalışmada; alg̨lanan yönetici desteğinin çalışanların işten ayrlma niyeti üzerindeki etkisi araştırllarak, bu ilişkide çalışanlarm iş stresinin üstlendiği aracılık rolü incelenmiştir. Araştırmanın veri seti; Adana ve Ankara illerindeki toplam 33 şehir otelinin çalışanlarından elde edilen 395 anketten oluşmaktadır. Elde edilen veriler, SPSS 24 programı ile analiz edilmiştir. Çalışmada; açımlayıcı faktör analizi, güvenilirlik, Pearson korelasyon, regresyon ve Sobel testi analizleri gerçekleştirilmiştir. Analiz sonuçlarına göre; çalışmaya katılanlar bakımından algılanan yönetici desteği çalı̧̧anların iş stresini anlamlı ve negatif bir şekilde, iş stresi ise çalışanların işten ayrlma niyetini anlamlı ve pozitif bir şekilde doğrudan etkilemektedir. Ayrıca algılanan yönetici desteği çalışanların işten ayrilma niyetini hem doğrudan hem de iş stresi üzerinden dolaylı olarak anlamlı ve negatif bir şekilde etkilemektedir. Çalışma kapsamında kurulan mekanizmada; iş stresinin kısmi aracılık rolü bulunmaktadır. Dolayısıyla bu çalışmada; algılanan yönetici desteği düzeyindeki artış sayesinde çalışanların işten ayrılma niyeti düzeyini hem doğrudan hem de bu çalışanların iş stresi düzeyindeki azalış yoluyla düşürmenin ve böylece örgüte katkı sağlamanın mümkün olduğu sonucuna ulaşılmaktadır.
\end{abstract}

Anahtar Kelimeler: Algılanan Yönetici Desteği, İş Stresi, İşten Ayrılma Niyeti, Şehir Oteli.

\footnotetext{
${ }^{1}$ Bu çalışma; 02-03 Kasım 2018 tarihlerinde Isparta'da gerçekleştirilen 6. Örgütsel Davranış Kongresi'nde sözlü bildiri olarak sunulan çalışmanın genişletilmiş halidir.
} 


\title{
The Role of Work Stress in The Relationship Between Perceived Supervisor Support and Intention to Quit
}

\begin{abstract}
This study examines the effect of perceived supervisor support on employees' intention to quit, and the mediating role of employees' work stress in this relationship. The data set of the research consists of 395 questionnaires obtained from the employees of 33 city hotels in Adana and Ankara. The data collected have been analyzed through SPSS 24 program. Exploratory factor analysis, reliability, Pearson correlation, regression and Sobel test analyses have been performed in this study. According to the analysis results in terms of participants in this study, perceived supervisor support directly affects the work stress of employees in a significant and negative way, while employees' work stress directly affects their intention to quit in a significant and positive way. In addition, perceived supervisor support affects employees' intention to quit both directly and indirectly through the work stress in a significant and negative way. Work stress has a partial mediating role in the mechanism established within the scope of the study. Therefore, it is concluded that it is possible to decrease the level of employees' intention to quit both directly and indirectly through a drop in the work stress level of these employees thanks to the increase in perceived supervisor support level and thus to contribute to the organization.
\end{abstract}

Keywords: Perceived Supervisor Support, Work Stress, Intention to Quit, City Hotel. 


\section{Giriş}

Bu çalışmanın temel amacı; algılanan yönetici desteği ile çalışanların işten ayrılma niyeti arasındaki ilişkide çalışanların iş stresinin aracılık etkisini araştırmaktır. Algılanan yönetici desteği, iş stresi ve işten ayrılma niyeti konuları hakkında örgütsel davranış alanında hem yerli hem de yabancı literatürde çok sayıda çalışma bulunmaktadır. Literatürde; algılanan yönetici desteği örgüte katkı sağlayan, işten ayrılma niyeti ise örgüte zarar veren unsurlar olarak görülmektedir. İşs stresinin makul bir seviyenin üzerine çıkması durumunda, örgüte zarar verdiği kabul görmektedir. Bu bağlamda, çalışma kapsamında; "algılanan yönetici desteği düzeyindeki artışın çalışanların iş stresi ve işten ayrılma niyeti düzeyleri üzerindeki düşürücü etkileri yoluyla iş stresi ve işten ayrılma niyetinin örgüt üzerindeki zarar verici etkilerini hafifleterek örgüte katkı sağlamak mümkün müdür?" sorusuna cevap aranmaktadır. Ayrıca Turunç ve Avcı (2015)'in gerçekleştirdiği çalışma yanında, kıyı ve şehir otellerinin çeşitli özelliklerinden de yararlanılarak çalışma kapsamında bazı tespitler ve çıkarımlar yapılmaktadır.

Turunç ve Avcı (2015)'in otel çalışanları üzerinde gerçekleştirdiği çalışmanın araştırma sonuçlarına göre; algılanan örgütsel destek ve liderüye etkileşimi kalitesi düzeylerindeki artışın çalışanların işten ayrılma niyeti düzeyini azalttığı belirlenmiştir. Çalışanların algılanan örgütsel destek ve lider-üye etkileşimi kalitesi düzeylerindeki artış, çalışanların iş stresi düzeyini azaltmakta, azalan iş stresi düzeyi ise çalışanların işten ayrılma niyeti düzeyini düşürmektedir. Algılanan örgütsel destek ve lider-üye etkileşimi kalitesi ile işten ayrılma niyeti arasındaki ilişkilerde çalışanların iş stresinin aracılık rolü bulunmaktadır. Turunç ve Avcı (2015) kıyı otelleri ve sezonluk işletme çalışanları üzerinde yapılan bu çalışmanın şehir oteli çalışanları üzerinde gerçekleştirilmesi durumunda farklı sonuçların elde edilebileceğini ileri sürmektedir.

Çalışanlar yöneticilerini örgütün temsilcisi olarak gördükleri için yöneticilerinin onlara karşı olumlu tutum ve davranışlarını, örgütsel destek kapsamında algilarlar (Rhoades ve Eisenberger, 2002). Lider-üye etkileşimi teorisi, liderlik sürecini; lider ve ast arasında kurulan ikili ilişkilere bağlı olarak açıklar. Düşük kaliteli bir ilişkide; astlar üstlerinden daha düşük düzeyde destek gördüklerini, yüksek kaliteli bir ilişkide ise 
daha yüksek düzeyde destek gördüklerini düşünürler (Çalışkan, 2009). Bu bilgiler 1şığında, yönetici desteğinin hem örgütsel desteğin temel öğesi hem de lider-üye etkileşiminin kalitesinin önemli bir belirleyicisi olduğu ifade edilebilir. Çalışma çerçevesinde; Turunç ve Avcı (2015)'in kurduğu modele yakın bir model kurulmuştur, ancak bu çalışmadan farklı olarak araştırma modelinde örgütsel destek ve lider-üye etkileşiminin kalitesi değişkenleri yerine bu kavramlarla yakından ilişkili olan yönetici desteği değişkenine yer verilmiştir. Ayrıca araştırma; Turunç ve Avcı (2015)'in çalışmasından hareketle şehir otellerinde çalışanlar üzerinde gerçekleştirilmiştir.

\section{Algılanan Yönetici Desteği}

Yönetici desteği, çalışanların ilk amirleri tarafından gördükleri desteği ifade etmektedir (Yoon ve Lim, 1999, s. 925). Algılanan yönetici desteği, çalışanların yöneticilerinin onları önemseme ve örgüte yaptıkları katkılara değer verme düzeylerine dair inançlarıdır (Pohl ve Galletta, 2016, s. 62). Diğer bir tanımda, yönetici ile çalışan arasındaki olumlu iş ilişkisi olarak ifade edilmiştir. Destekleyici yöneticilerin çalışanları, ihtiyaçlarını karşılayarak motive ettikleri ve daha iyi çalışmaya yönlendirdikleri belirtilmiştir (Bhanthumnavin, 2003). Bir başka tanıma göre yönetici desteği, çalışanlara destek olunması, ilgi gösterilmesi, onların teşvik edilmesi ve cesaretlendirilmesidir (Babin ve Boles, 1996, s. 60). Bhanthumnavin (2000) yönetici desteğini bilgisel, maddi ve duygusal anlamda ele almaktadır. Yönetici desteği bilgisel anlamda değerlendirildiğinde; işe ilişkin konulara odaklanılmakta ve çalışanların verimliliğini arttırmak için gerekli olan ödül, ceza, takdir, geri bildirim, rehberlik etme ve işe ilişkin bilgi ve becerileri kapsamaktadır. Maddi anlamda; teçhizat, yardım, zaman, kaynak, servis hizmetleri, mal ve finansal yardım konularını kapsamaktadır. Yönetici desteği duygusal anlamda ise grup çalışmasında, iş motivasyonu arttırmada ve kaliteli bir iş ortamını sağlamada önemli bir rol üstlenmektedir. Bu anlamda yönetici desteği; yöneticilerin çalışanlarına ilgi, sevgi, saygı göstermesi, değer vermesi, onları kabul etmesi, onlara stres, çatışma ve iş ortamında karşılaştıkları zorluklarla başa çıkabilmeleri için gerekli yardım ve desteği vermeleri olarak ifade edilmiştir. Ayrıca duygusal anlamda desteğin, sözlü olabileceği gibi kucaklama, sarılma, el sıkışma gibi 
sözlü olmayan biçimde de gerçekleşebileceği belirtilmiştir (Bhanthumnavin, 2000, s.160). Bu destek türlerinden bir ya da daha fazlasının sağland1ğının algılandığı bir iş ortamında üst ile ast arasındaki kişilerarası davranış yönetici desteği olarak ifade edilmektedir (Bhanthumnavin, 2003). Yönetici desteğine ilişkin yapılan tanımlamalar, yöneticilerin çalışanlarına ihtiyaçları doğrultusunda destek vererek, aslında hedeflere ulaşmakta çalışanların sunacağı katkıyı arttırmayı amaçladığını göstermektedir. Bu kapsamda, karşılıklı etkileşime dayalı bu ilişki bünyesinde "Karşılıklılık Normu" nu (The Norm of Reciprocity- Gouldner, 1960) içeren "Sosyal Değişim Teorisi" (Social Exchange Theory- Blau, 1964) akla gelmektedir. Bu teori çerçevesinde, yönetici ile çalışan arasındaki olumlu ve faydalı eylemler; taraflar arasında zorunluluk hissi yaratarak yüksek kalitede değiş-tokuş ilişkisinin oluşmasını sağlamaktadır (Settoon, Bennett ve Liden, 1996). Bu teoriye göre; çalışanların sadakatleri ve çabaları karşılığında onlara sunulan maddi ve sosyal ödüller değiş-tokuş edilmektedir (Hutchison, 1997). Yapılan araştırmalar algılanan yönetici desteğinin içsel motivasyonu (Khalid, Rathore ve Aslam, 2017), mutluluğu (Bardakoğlu, Akgündüz, Kızılcalığlu ve Yeşilyurt, 2017), lider-üye etkileşiminin kalitesini (Özkara, Taş ve Aydıntan, 2019), iş tatminini (Qureshi ve Hamid, 2017), performansı (Azman, Sieng, Ajis, Dollah ve Boerhannoeddin, 2009), örgüte bağlılığ1 ve örgütsel vatandaşlık davranışlarını (Wang, 2014) arttırdığı, buna karşın örgütsel sinizmi (Özkara, Taş ve Aydıntan, 2019) ve tükenmişliği (Salahian, Oreizi, Abedi, Soltani, 2012) azalttığı tespit edilmiştir.

\section{İş Stresi}

Schermerhorn'a göre stres; olağanüstü talepler, sinırlamalar veya firsatlarla karşı karşıya kalındığında birey tarafından yaşanan bir gerilim durumudur (Aktaran Aydın, 2016). Stres kavramı genellikle bireyde sıkıntı yaratan olaylar karşısında yaşanan bir tepki süreci olarak kabul edilmektedir (Aydın, 2016). Bir başka tanıma göre stres; bilinçli veya bilinçsiz olarak, kişinin başa çıkabilme kapasitesinin ötesinde algılanan bir tehdit veya istenmeyen bir duruma karşı fizyolojik ve psikolojik tepki olarak belirtilmiştir (Chiang, Birtch ve Kwan, 2010, s. 26). Stres kavramının fizyolojik ve 
psikolojik açıklamalarının ortak noktası "uyumsuzluktur". Buna göre; birey ile iç ve dış ortamdan kaynaklanan etkenler arasında daima bir etkileşim vardır. Belirli sınırlar ve ölçülerden sonra bu etkenler bireyin uyumunu bozabilmektedir. Bu uyumun bozulması, psikolojik anlamda, tutumların tutarsızlığına yol açar; bu konudaki tutarsızlık ve dengesizlik "zihinsel uyumsuzluk" yoluyla bireyde baskı ve sıkıntı yaratır. Fizyolojik ya da psikolojik temelde ortaya çıkan uyumsuzlukların bunların sonuçlarının ve bu sonuçların giderilmesiyle ilgili çabaların bütününe "stres" adı verilmektedir (Eroğlu, 2015, s. 509). İş stresi ise "bireyin, iş yerinde kapasitesini veya kaynaklarını aşan bir duruma yönelik psikolojik tepkisi" olarak tanımlanabilir (LePine, LePine ve Jackson, 2004, s.883). İş çevresine ilişkin stres kaynakları; görev yapısına ilişkin stres kaynakları (aşırı iş yükü, işin sıkıcı olması, ücret yetersizliği, yükselme olanağı, çalışma saatlerinin uzun olması, çalışma koşulları, kalabalık), yetke yapısına ilişkin stres kaynakları (karar verme, karara katılma, yetkilerin yetersiz oluşu, sorumlulukların verdiği endişe, değerlendirmede adaletsizlik, yöneticilerin teşvik etmemesi) ve üretim yapısına ilişkin stres kaynakları (zaman baskısı, araç-gereç yetersizliği, yeteneklerin işin gereklerine uygun olmaması, çalışmaların karşılığını alamamak) olmak üzere üç grupta toplanabilir (Aydın, 2016). Stres; bireysel ve örgütsel düzeyde ciddi sonuçlar doğurmaktadır. Bireysel anlamda; fizyolojik hastalıklara (baş ağrısı, uyku bozukluğu), psikolojik rahatsızlıklara (endişe, depresyon, öfke, unutkanlık, çaresizlik hissi) ve davranışsal bozukluklara (alkol, sigara, uyku hapı kullanımı, saldırgan davranışlar, iş kazaları) neden olmaktadır (Gillespie, Walsh, Winefield, Dua ve Stough, 2001, s.65-66; Ross ve Altmaier, 1994, s. 12-13). Diğer taraftan, iş stresinin örgütsel çıtılarla ilişkisini inceleyen çalişmalarda, iş stresinin iş tatmini (O'Neill ve Davis, 2011), performans (Irawanto, Noermiyati ve Primasari, 2015) ve örgüte bağlllı̆̆1 (Bhatti, Bhatti, Akram, Hashim ve Akram, 2016) azalttığı; tükenmişlik (Khattak, Khan, Haq, Arif ve Minhas, 2011) ve devamsızlığ1 (Vasse, Nijhuis ve Kok, 1998) arttırdığı tespit edilmiştir.

\section{Algılanan Yönetici Desteği ile İş Stresi Arasındaki İlişki}

Literatürde yönetici desteği ile iş stresi arasında negatif ilişki olduğu (Cummins, 1990; Yang vd., 2016; Naidoo, 2018); yönetici desteğini yüksek 
algılayan çalışanların daha az iş stresi yaşadıkları ortaya konulmuştur (Bardakoğlu vd., 2017; Wickramasinghe, 2012). Nitekim, Kaynakların Korunması Kuramı (Conservation of Resources theory-Hobfoll, 1989)' a göre; bireylerin stres yaşamalarının üç temel nedeni vardır. Bireyler kendileri için değerli gördükleri kaynakları elde etmek, ellerinde tutmak ve korumak isterler. Bu kaynakların kaybolması, tehdit edilmesi ya da beklenilen seviyede elde edilememesi bireylerin stres yaşamalarına neden olmaktadır (Hobfoll, 1989). Öte yandan yöneticileri tarafından değer gördüklerini, iyilik ve mutluluklarının önemsendiğini düşünen bireylerin iş ortamında bir takım güçlüklerle karşı karşıya kaldıklarında yönetici desteği gibi bir kaynağa sahip olduklarına ve bu kaynağa erişebileceklerine dair inancı işyerindeki stresörlerin olumsuz etkisinin azalmasını sağlayabilecektir.

Çalışma kapsamında; teorik bilgiler ve ampirik çalışmalardan hareketle algılanan yönetici desteğinin iş stresini anlamlı ve negatif bir şekilde etkilemesi beklenmektedir.

\section{İşten Ayrılma Niyeti}

Psikolojik olduğu kadar, sosyolojik ve ekonomik anlamda da olumsuz sonuçlar doğuran işten ayrılma niyeti, çalışanın kurumundan ayrılma arzusu ve planı olarak ifade edilmiştir (Timinepere, Agbaeze, Ogbo ve Uche, 2018, s.150). Başka bir tanımda, işten ayrılma niyeti çalışanın belirli bir süre çalışmakta olduğu işinden istifa etme olasılığı olarak ifade edilmiştir (Fong ve Mahfar, 2013, s.35). Tett ve Meyer (1993, s.262) işten ayrılma niyetini, bilinçli ve kasıtlı bir şekilde işten ayrılma düşüncesi olarak tanımlamışlardır. Rusbult, Farrell, Rogers ve Mainous (1988, s.601) işten ayrılma niyetini, çalışanların istihdam koşullarından tatminsiz olmaları durumunda gösterdikleri yıkıcı ve aktif bir eylem olarak ifade etmişlerdir. Özdemir ve Özdemir (2015, s.337) ise işten ayrılma niyetini bireysel ya da örgütün çalışanların beklentilerini karşılayamaması gibi örgütsel nedenlerle çalışanlarda oluşan iş ilişkisini sona erdirme, işi bırakma, örgütü terk etme isteği olarak tanımlamışlardır (Özdemir ve Özdemir, 2015). Bu kapsamda; bireylerde işten ayrılma niyetinin yüksek olması ve bunun davranışa dönüşmesi sonucunda işgören devir hıznın artması, örgütler için verimlilik ve karlılık konularında büyük kayıplara yol açmaktadır. Perez, 
yönetici desteğinin, esnek çalı̧̧manın, katılımın, iş özerkliğinin ve iş koşullarının işten ayrılma niyetinin belirleyicileri olduğunu belirtmiştir (Aktaran Fong ve Mahfar, 2013, s. 35). Bu noktada; çalışanlarda işten ayrılma niyetinin önlenebilmesi için çeşitli yöntemlerin kullanılması gerekmektedir. Söz konusu yöntemler arasında çalışanlar tarafından algılanan yönetici desteğinin arttırılması çözüm olarak düşünülebilir.

\section{Algılanan Yönetici Desteği ile İşten Ayrılma Niyeti Arasındaki İlişki}

Literatürdeki çalışmalara (örn.: Yüksel, 2006; Kalemci Tuzun ve Kalemci, 2012) göre; algılanan yönetici desteği ile işten ayrılma niyeti arasında negatif yönlü bir ilişki bulunmaktadır ve algılanan yönetici desteğindeki artı̧̧ işten ayrılma niyetini azaltmaktadır (örn.: Afacan Findıklı, 2014; Dysvik ve Kuvaas, 2013; Kalidass ve Bahran, 2015; Newman, Thanacoody ve Hui, 2012; Nichols, Swanberg ve Bright, 2016).

Bu bilgiler ışığında, çalışma kapsamında; algılanan yönetici desteğinin işten ayrılma niyetini anlamlı ve negatif bir şekilde etkilemesi beklenmektedir.

\section{İş Stresi ile İşten Ayrılma Niyeti Arasındaki İlişki}

Çeşitli sektörlerde (otel, eğitim, tekstil) görev yapan katılımcılar üzerinde iş stresi ile işten ayrılma niyeti arasındaki ilişkilerin incelendiği çalışmalarda (Akova, Emiroglu ve Tanriverdi, 2015; Savaş ve Erol, 2017; Qureshi vd., 2013); iş stresinin işten ayrılma niyetini arttırdığı tespit edilmiştir. Aynı bulgu farklı organizasyonlarda çalışan katılımcılar (sondaj çalışanları, pazarlama yöneticileri, makine operatörleri,) üzerinde yapılan çalışmalarda (Arshadi ve Damiri, 2013; Noor ve Maad, 2008; Sewwandi ve Perere, 2016) da desteklenmiştir.

Bu bilgiler ışığında, çalışma kapsamında; iş stresinin işten ayrılma niyetini anlamlı ve pozitif bir şekilde etkilemesi beklenmektedir.

\section{Yöntem}


$\mathrm{Bu}$ çalışmanın yöntem kısmında; araştırma modeline, hipotezine, örnekleme, veri toplama araçlarına, çalışmada kullanılan istatistiklerin hangi programlarda hangi sırada yapıldığına yani işleme yer ve rilmektedir.

\section{Araştırma Modeli ve Hipotezi}

Çalışmanın buraya kadarki kısmında açıklanan teorik bilgiler ve ampirik çalışmalardan hareketle iş stresinin yönetici desteği ve işten ayrılma niyeti arasındaki ilişkiye aracılık ettiği, bir başka deyişle yönetici desteğinin iş stresini azaltarak işten ayrılma niyeti üzerinde azaltıcı etkisi olduğu söylenebilir. Tüm bu bilgiler ışığında Şekil 1'de görüldüğü üzere çalışmanın araştırma modeli kurulmuş ve hipotezi geliştirilmiştir:

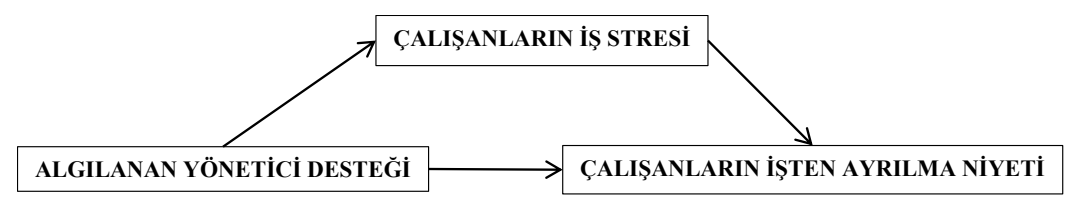

Şekil 1. Araştırma Modeli

Hipotez: Algılanan yönetici desteği ile çalışanların işten ayrılma niyeti arasındaki ilişkide bu çalışanların iş stresinin aracılık etkisi vardır.

\section{Örneklem ve Veri Toplama Araçlan}

Kolayda örnekleme yoluyla 17'si Adana ve 16'sı Ankara'da olmak üzere toplam 33 şehir otelinde çalışan 684 kişiye anket dağıtılmıştır; ancak 512 kişiden geri dönüş olmuştur. Geri dönüş oranı yaklaşı \% $\% 5^{\prime}$ tir. 512 anketin sadece 395'i araştırmada kullanılabilir niteliktedir. Araştırmanın veri seti büyüklüğü, ön analizler tamamlandıktan sonra kesinleşecektir. Alg1lanan yönetici desteğini ölçmek için Giray ve Şahin (2012) tarafından geliştirilen 11 maddelik ölçek kullanılmıştır. İş stresini ölçmek için House ve Rizzo (1972) tarafından geliştirilen ve Efeoğlu (2006) tarafından Türkçe'ye uyarlanan 7 maddelik ölçekten yararlanılmıştır. İşten ayrılma niyetini ölç- 
mek için ise Wayne, Shore ve Liden (1997) tarafından geliştirilen ve Küçükusta (2007) tarafından Türkçe'ye uyarlanan 3 maddelik ölçekten faydalanılmıştır. Bu ölçeklerde cevaplar 5'li Likert ölçeği üzerinde verilmiştir. Anket formunda demografik sorular da yer almaktadır.

\section{İşlem}

Nicel bir araştırmanın gerçekleştirildiği bu çalışmada; anket yöntemiyle veri toplanmıştır. İlk olarak, "SPSS 24" programı kullanılarak veri girişi yapılmıştır. Veri setinin kontrolü ve analize hazırlanması (ön analizleri) tamamlandıktan sonra, araştırmaya katılanların demografik özellikleri belirlenmiştir. Daha sonra yapı geçerliliği açımlayıcı faktör analizi ile sinanmıştır. Akabinde, "SPSS 24" programı kullanılarak araştırma modelindeki değişkenlerin ortalama ve standart sapma değerleri hesaplanmış, güvenilirlik, Pearson korelasyon ve regresyon analizleri yapılmıştır. Son olarak interaktif ortamda Sobel testi gerçekleştirilmiştir.

\section{Bulgular}

Bu çalışmanın bulgular kısmında; ön analizlere, katılımcılara ilişkin betimsel bulgulara, geçerlilik, güvenilirlik, korelasyon analizlerine ve araştırma hipotezinin test edilmesine yer verilmektedir.

\section{Ön Analizler}

Tabachnick ve Fidell (2013)'ün önerisi dikkate alınarak veri setinin doğruluğu, eksik veri analizi, normallik testi ve çoklu bağlantı analizi olmak üzere dört aşamada veri setinin kontrolü ve analize hazırlanması süreci tamamlanmıştır. Tüm ölçek maddelerine ait basıklık ve çarpıklık değerleri incelendiğinde -1.5 ile +1.5 değerleri arasında değiştiği tespit edilmiş ve böylece verinin normal dağılım özelliğine sahip olduğu kabul edilmiştir. Ön analizler sonucunda; araştırmanın veri seti büyüklüğü 395 olarak kesinleşmiştir. Saunders, Lewis ve Thornhill (2009)'a göre; 384 katılımcı \%95 güven aralığında \%5 hata payı ile 1.000 .000 ve üzeri evren büyüklüğünü temsil etmektedir. Bu çalışmanın veri seti büyüklügünün 395 
olduğu dikkate alındığında, bu sayı Adana ve Ankara' daki şehir oteli çalışanlarını yani evreni temsil eder niteliktedir.

\section{Katılımcılara İlişkin Betimsel Bulgular}

Araştırmanın veri setini oluşturan katılımcıların demografik özellikleri sıklık ve yüzde bazında Tablo 1'de görülmektedir.

Tablo 1. Araştırmanın Veri Setini Oluşturan Katılımcıların Demografik Özellikleri

\begin{tabular}{lcc}
\hline Demografik Özellikler & S1klık $(\mathbf{n})$ & Yüzde(\%) \\
\hline Cinsiyet & & \\
\hline Kadın & 140 & 35.4 \\
Erkek & 255 & 64.6 \\
\hline Yaş & & \\
\hline 20 yaşın altı & 12 & 3.0 \\
20-29 yaş & 126 & 31.9 \\
30-39 yaş & 145 & 36.7 \\
40-49 yaş & 102 & 25.8 \\
50 yaş ve üzeri & 10 & 2.5 \\
\hline Eğitim Düzeyi & & \\
\hline İköğretim & 80 & 20.3 \\
Lise & 189 & 47.8 \\
Ön lisans & 59 & 14.9 \\
Lisans & 60 & 15.2 \\
Lisansüstü & 7 & 1.8 \\
\hline İş Yerinde Çalışma Süresi & & \\
\hline 1 ylldan az & 141 & 35.7 \\
1-3 yll & 109 & 27.6 \\
4-6 yll & 85 & 21.5 \\
7-9 yll & 60 & 15.2 \\
\hline
\end{tabular}

Tablo 1'de de görüldüğü üzere katılımciların \%35.4'ü kadın, \%64.6's1 erkektir. Bu oranlar erkeklerin kadınlara göre çok daha fazla olduğunu göstermektedir. Araştırmaya katılan çalışanların \%3'ü 20 yaşın altı, \%31.9'u 20-29 yaş, \%36.7'si 30-39 yaş, \%25.8'i 40-49 yaş aralığında, \%2.5'i ise 50 yaş ve üzerindedir. Katılımcıların küçük bir kısmı 20 yaş altındadır. En fazla katılımcı sayısı 30-39 yaş aralığındadır. Katılımcıların eğitim düzeylerine bakıldığında \%20.3'ünün ilköğretim, \%47.8'inin lise, $\% 14.9^{\prime}$ unun ön lisans, \%15.2'sinin lisans ve \%1.8'inin lisans üstünde mezun olduğu görülmektedir. Katılımcıların çoğunluğu lise mezunlarından 
oluşmaktadır. Katılımcıların kurumda çalışma süreleri incelendiğinde ise \%35.7'sinin 1 yıldan az bir süredir, \%27.6'sının 1-3 yıl, \%21.5'inin 4-6 yıl ve \%15.2'sinin 7-9 yıl arasında kurumlarında görev yaptıkları belirlenmiştir. 1 yıldan az görev yapanların sayısı oldukça fazladır.

\section{Geçerlilik Analizi}

Çalışma kapsamında; araştırma modelindeki üç farklı değişkene ait tüm maddeler SPSS 24 programında bütün bir yapıda açımlayıcı faktör analizine tabi tutulmuştur.

Tablo 2. Açımlayıcı Faktör Analizi Sonuçları

\begin{tabular}{llll}
\hline Maddeler & Faktörler & $\mathbf{2}$ & 3 \\
\hline AYD1 & $\mathbf{1}$ & & \\
AYD2 & .762 & & \\
AYD3 & .812 & & \\
AYD4 & .772 & & \\
AYD5 & .798 & & \\
AYD6 & .775 & & \\
AYD7 & .696 & & \\
AYD8 & .792 & & \\
AYD9 & .786 & & \\
AYD10 & .805 & & \\
AYD11 & .770 & .628 & \\
IS1 & .718 & .715 & .793 \\
İS2 & & .701 & .850 \\
IS3 & & .753 & \\
IS4 & & .728 & \\
İS5 & & .639 & \\
IS6 & & .540 & \\
İS7 & & & \\
İAN1 & & & \\
IAN2 & & & \\
İAN3 & & & \\
\hline
\end{tabular}

Notlar: KMO: 0.882; Barlett Küresellik Testi [ $\left.\chi^{2}(210)=5442.685 ; p<0.001\right]$; Toplam Açılanan Varyans: \%62.113; Kısaltmalar: AYD: Algzlanan Yönetici Desteği; IS: İ̧s Stresi; İAN: İşten Ayrlma Niyeti

Tablo 2'deki KMO Barlett's Test sonucunun 0.50'nin üzerinde olması ve Barlett küresellik testi sonucunun da anlamlı çıkması veri setine açımlayıcı faktör analizi uygulanabileceğini göstermektedir (Kalaycı, 2010). Analiz sonuçlarına göre; çalışmanın araştırma modelindeki üç 
değişkene ait maddeler teorilerine uygun bir şekilde değişkenlerin altında toplanmakta ve bu değişkenler toplam varyansın yaklaşık \%62' sini açıklamaktadır. Bu oran; literatürde kabul edilen \%50 oranının üzerindedir. Ayrıca maddelere ilişkin hesaplanan en küçük faktör yükü değeri .540'tır. $\mathrm{Bu}$ değer de literatürde minimum değer olarak kabul gören .40 değerinden büyüktür (Hair, Black, Babin ve Anderson, 2010). O halde; araştırma kapsamındaki tüm ölçeklerin geçerliliği sağlanmıştır.

\section{Güvenilirlik ve Korelasyon Analizleri}

Çalışmada yer alan değişkenlerin ortalama ve standart sapmaları ile korelasyon katsayıları Tablo 3'de görülmektedir.

Tablo 3. Araştırma Değişkenlerine İlişkin Tanımlayıcı İstatistikler, Güvenilirlik ve Korelasyon Analizi Sonuçları

\begin{tabular}{lllllll}
\hline Değişkenler & Ort. & SS & $\mathbf{1}$ & $\mathbf{2}$ & $\mathbf{3}$ & $\mathbf{4}$ \\
\hline Cinsiyet & - & - & - & & & \\
Algılanan Yönetici Desteği & 3.69 & .96 & -.02 & $(.93)$ & & \\
İş Stresi & 2.65 & .95 & .03 & $-.31^{* *}$ & $(.81)$ & \\
İşten Ayrılma Niyeti & 2.46 & 1.25 & -.03 & $-.32^{* *}$ & $.45^{* *}$ & $(.90)$ \\
\hline
\end{tabular}

Notlar: ${ }^{*} p<.01$; Parantez içindeki değerler Cronbach Alpha güvenilirlik katsayısıdır.

Yapılan korelasyon analizi sonucunda; algılanan yönetici desteği ile iş stresi arasında anlamlı ve negatif yönlü bir ilişki ( $r=-.31 ; \mathrm{p}<.01)$, algılanan yönetici desteği ile işten ayrılma niyeti arasında da anlamlı ve negatif yönlü bir ilişki $(\mathrm{r}=-.32 ; \mathrm{p}<.01)$, iş stresi ile işten ayrılma niyeti arasında ise anlamlı ve pozitif yönlü bir ilişki $(\mathrm{r}=.45 ; \mathrm{p}<.01)$ olduğu belirlenmiştir.

Algılanan yönetici desteği, iş stresi ve işten ayrılma niyeti ölçeklerine ait Cronbach Alpha güvenilirlik katsayıları sırasıyla $.93, .81$ ve .90 'dır. Dolayısıyla tüm ölçeklerin güvenilirlikleri kabul edilebilir .70'lik Cronbach Alpha düzeyinin üzerinde değerlere sahiptir (Hair vd., 2010).

Araştırma Hipotezinin Test Edilmesi: Çalışmanın araştırma hipotezinin testi için yapılan hiyerarşik regresyon analizinde (Tablo 4) Baron ve Kenny (1986) tarafından önerilen yöntem takip edilmiştir. Algılanan yönetici desteği çalışanların işten ayrılma niyetini negatif ve anlamlı bir şe- 
kilde etkilemektedir $(\beta=-.324 ; \mathrm{p}<.01)$. O halde; aracilığa ilişkin birinci koşul sağlanmıştır. Ayrıca algılanan yönetici desteğinin çalışanların iş stresi üzerinde negatif ve anlamlı bir etkisi bulunurken $(\beta=-.312 ; \mathrm{p}<.01)$, çalışanların iş stresi işten ayrılma niyetini pozitif ve anlamlı bir şekilde etkilemektedir $(\beta=.397 ; \mathrm{p}<.01)$. Böylece aracılığa ilişkin ikinci ve üçüncü koşullar da sağlanmıştır.

Tablo 4. Regresyon Analizi Sonuçları

\begin{tabular}{|c|c|c|c|c|c|c|c|}
\hline $\begin{array}{l}\text { Bağımsız } \\
\text { Değişken }\end{array}$ & Bağımlı Değişken & Beta & $T$ & $p$ & $\mathbf{R}$ & $\mathbf{R}^{2}$ & F \\
\hline $\begin{array}{l}\text { Algilanan } \\
\text { Yönetici } \\
\text { Desteği }\end{array}$ & $\begin{array}{l}\text { İşten Ayrılma } \\
\text { Niyeti }\end{array}$ & $-.324^{* *}$ & -6.791 & .000 & .324 & .105 & 46.119 \\
\hline $\begin{array}{l}\text { Algılanan } \\
\text { Yönetici } \\
\text { Desteği }\end{array}$ & İş Stresi & $-.312^{* *}$ & -6.500 & .000 & .312 & .097 & 42.255 \\
\hline İş Stresi & $\begin{array}{l}\text { İşten Ayrılma } \\
\text { Niyeti }\end{array}$ & $.397^{* *}$ & 8.608 & .000 & .497 & .247 & 64.393 \\
\hline $\begin{array}{l}\text { Algılanan Yö- } \\
\text { netici Desteği }\end{array}$ & $\begin{array}{l}\text { İşten Ayrılma } \\
\text { Niyeti }\end{array}$ & $-.200^{* *}$ & -4.346 & .000 & .497 & .247 & 64.393 \\
\hline İş Stresi & & $.459^{* *}$ & 10.253 & .000 & .459 & .211 & 105.119 \\
\hline
\end{tabular}

$p<.01^{* *}$

İş stresi regresyon denklemine dahil edildiğinde algılanan yönetici desteği çalışanların işten ayrılma niyetini negatif ve anlamlı bir şekilde hâlâ etkilemektedir; ancak bu etki azalmıştır $(\beta=-.200$ p<.01). Bu durum; Baron ve Kenny (1986)'ya göre iş stresinin algılanan yönetici desteği ile işten ayrılma niyeti arasındaki ilişkide kısmi aracilık etkisinin olduğu sonucuna işaret etmektedir. $O$ halde, aracilığa ilişkin dördüncü koşul da sağlanmıştır. Aracılığa ilişkin dört koşul sağlandıktan sonra, son olarak aracılık etkisinin anlamlı olup olmadığının belirlenmesi amacıyla Sobel testi yapılmıştır. Gerçekleştirilen Sobel testi sonucunda (Preacher ve Leonardelli, 2010); algılanan yönetici desteği ve işten ayrılma niyeti arasındaki ilişkide iş stresinin aracılık etkisinin istatistiksel olarak anlamlı olduğu saptanmıştır ( $Z=-5.22 ; \mathrm{p}<.001)$. Dolayısıyla araştırma hipotezi desteklenmiştir. Ayrıca kurulan bu mekanizmada iş stresi değişkeni kısmi aracılık rolüne sahiptir.

\section{Tartışma ve Sonuç}


Bu çalışmada elde edilen bulgulara göre; literatüre uygun olarak algılanan yönetici desteği çalışanların iş stresini anlamlı ve negatif bir şekilde, iş stresi ise çalışanların işten ayrılma niyetini anlamlı ve pozitif bir şekilde doğrudan etkilemektedir. Ayrıca algılanan yönetici desteği işten ayrılma niyetini hem doğrudan hem de iş stresi üzerinden dolaylı olarak anlamlı ve negatif bir şekilde etkilemektedir. Dolayısıyla algılanan yönetici desteği ile işten ayrılma niyeti arasındaki ilişkide iş stresinin kismi aracılık rolü bulunmaktadır. O halde; algılanan yönetici desteği düzeyindeki artış sayesinde çalışanların işten ayrılma niyeti düzeyi hem doğrudan hem de bu çalışanların iş stresi düzeyindeki azalış yoluyla düşürülebilir. Tüm bu bilgiler ışı̆̆ında; algılanan yönetici desteği düzeyindeki artışın çalışanların iş stresi ve işten ayrılma niyeti düzeyleri üzerindeki düşürücü etkileri yoluyla iş stresi ve işten ayrılma niyetinin örgüt üzerindeki zarar verici etkilerini hafifleterek örgüte katkı sağlamanın mümkün olduğu sonucuna ulaşılmaktadır.

Çalışma kapsamında elde edilen sonuçlar Turunç ve Avcı (2015)'in çalışmasındaki sonuçlarla benzerlik göstermektedir. Benzer sonuçların elde edilmesinde stres faktörünün etkili olduğu düşünülmektedir. Literatürde; şehir ve kıyı otelleri, konaklama işletmeleri kapsamında ele alınmaktadır (Bilici, 2009). Dinlenmek, eğlenmek, tatil yapmak amaçlarına yönelik olarak faaliyet gösteren dağ otelleri, termal oteller, deniz kenarında kurulan kıyı otelleri sayfiye (resort) otel kapsamındadır. Şehir otelleri ise şehir merkezlerinde, özellikle büyük şehirlerde, iş ve ticaret merkezlerine yakın yerlerde kurulan otellerdir. Sayfiye otellerin bulunduğu yere göre faaliyet süresi değişmektedir; bazı dönemlerde bu otellere aşırı yoğun bir talep söz konusuyken, bazı dönemler de ise talep neredeyse tamamen bitmektedir. Şehir otellerinin, sayfiye otellerinden en önemli farklarından birisi de şehir otellerinde genellikle iş dünyasından insanlarla, konferans, kongre, toplantı gibi etkinliklere katılan müşterilerin konaklaması nedeniyle bu otellerin tüm sene boyunca faaliyette olmasıdır (Oral ve Kurgun, 1997). Bu bilgilerden hareketle; şehir otellerinde konaklayan müşteri profilinin kıyı otellerine göre sosyo-ekonomik açıdan değerlendirildiğinde hem maddi bakımdan hem de eğitim bakımından daha elit bir tabakadan oluştuğu ifade edilebilir. Görüldüğü üzere kıyı ve 
şehir otelleri çeşitli yönlerden birbirlerinden ayrışmakta ve farklı özellikler taşımaktadır. Bununla birlikte Bilici'ye göre; hem şehir hem de kıyı otellerinde çalışma şartları nedeniyle çalışanda stres ortaya çıkmaktadır (Bilici, 2009). Ancak bu otel tiplerinin kuruluş amaçları, işleyişleri ve müşteri profilleri arasındaki farklılıklar nedeniyle ilgili otellerde çalışanların stres kaynaklarının yani stresörlerinin ayrıştı̆̆ söylenebilir. Bu noktada; ilgili stresörlerin tespit edilmesi ve ortadan kaldırılması doğrultusundaki yönetici tutum ve davranışları, örgütsel başarının yakalanması yani örgütsel etkililiğin ve verimliliğin sağlanması için büyük önem arz etmektedir.

Kıyı ve şehir otel tiplerinin kuruluş amaçları, işleyişleri ve müşteri profilleri arasındaki farklılıklardan ve çeşitli gözlemlerden hareketle ilgili otel tiplerinde görülen stres kaynaklarının neler olabileceği adına çeşitli çıkarımlarda bulunmak mümkündür. Kıyı otelleri özellikle turizm sezonunda aşırı derecede yoğundur. Aşırı yoğunluk çalışanların iş yükünü arttırır ve stres düzeylerini yükseltir. Ayrıca bu tip otel çalışanlarının önemli bir bölümü turizm sezonu dışında işten çıkarılmaktadır. Çalışanların gelecekte işlerini kaybedebilecekleri endişesini duymaları onları strese sokabilmektedir. Şehir otellerinde ise genellikle aşırı bir yoğunluk beklenmemektedir. Buna karşın şehir otellerinin müşteri profili kıyı otel tipine göre daha elit bir tabakadan oluştuğu için şehir oteli müşterilerinin sunulan hizmetin kalitesine ve devamlılığına dair beklentisinin kıyı otel tipi müşterilerine göre daha büyük olması beklenebilir. Şehir otellerinin aynı kişilerden oluşan bir müşteri profiline sahip olduğu ve bu kişilerin kısa süreli konakladıkları söylenebilir. Kısa süreli konaklayan bu kişileri kaldığ 1 süre içerisinde memnun etmek bu müşterilerin otele tekrar gelmeleri bakımından önemlidir. Evlerindeki rahatlığı otelde de yaşamak isteyen bu kişilerin kalitede yüksek standardın yakalanmasına ve sürdürülmesine yönelik beklentisi şehir oteli çalışanlarını müşteriler tarafından otel yönetimine şikayet edilme, amirleri tarafından tenkit edilme ve işten atılma korkusuyla strese sokabilmektedir. Yöneticinin müşteri beklentilerinin karşılanması adına çalışanlarına vereceği destek örgütsel başarının yakalanmasına katkı sağlayacaktır. Yönetici desteğinin yetersiz kalması durumunda; çalışanların stres düzeyi ve buna bağlı olarak işten ayrılma niyeti düzeyi yükselecektir. İşten ayrılma niyetinin eyleme dönüşmesi ise kalitede yüksek standardı ve sürekliliği hedefleyen bir işletme için büyük 
bir sorun teşkil edebilir. Çünkü işten ayrılan kişinin yerine o işi yapabilecek nitelikte bir kişinin seçilip yerleştirilmesi ve oryantasyonu zaman alacaktır. Bu durumun; özellikle şehir otellerinde örgütsel etkililik ve verimliliği düşürmesi beklenebilir.

Her çalışmada olduğu gibi bu çalışmada da bazı kısıtlar mevcuttur. Elde edilen bulgular, araştırmaya katılmayı kabul eden otel çalışanları bakımından geçerlidir. Araştırma modeli farklı sektörlerde çalışanlar üzerinde de test edilebilir. Araştırmanın yapıldığı dönemde iş gücü devir hızı yüksektir. Bu nedenle veri setinde 1 yıldan az süredir çalışanların oranı üçte birden büyüktür. Arzu edilmeyen bu durum veri setine yansımıştır. Araştırmanın bir diğer kısıtı veri toplama yöntemi ile ilgilidir. İleriki çalışmalarda görüşme, gözlem gibi veri toplama yöntemleriyle nitel veri analizi uygulanarak araştırma değişkenlerine ve bu değişkenler arasındaki ilişkilere dair daha detaylı sonuçlar elde edilebilir. Son olarak, araştırmadaki değişkenler (algılanan yönetici desteği, iş stresi, işten ayrılma niyeti) bakımından sınırlılık mevcuttur. Bu değişkenler arasındaki ilişkilerde çalışanların kişisel özelliklerinin de önem arz edebileceği unutulmamalıdır. İleriki çalışmalarda; kişilik özellikleri (A tipi, B tipi kişilik, psikolojik dayanıklılık) ve demografik özellikler yanında güven ve iş güvencesi gibi farklı değişkenler modele dahil edilerek model genişletilebilir. 


\title{
EXTENDED ABSTRACT
}

\section{The Role of Work Stress in the Relationship between Perceived Supervisor Support and Intention to Quit}

\author{
* \\ Aynur Taş-Zülfi Umut Özkara \\ Hakkari University, Ankara Hacı Bayram Veli University
}

The basic objective of this study is to investigate the mediating role of employees' work stress in the relationship between the perceived supervisor support and employees' intention to quit. In the literature; perceived supervisor support is considered as factors that contribute to the organization while intention to quit is considered as factors that impair the organization. It is considered that the work stress impairs the organization when it rises above a reasonable level. In this context, the study seeks answer to the question; "is it possible to diminish the impairing impacts of the work stress and the intention to quit on the organization through mitigating effects of the increase in perceived supervisor support level on the employee's work stress and intention to quit levels, and thus to contribute to the organization?" Furthermore, in addition to the study conducted by Turunç and Avc1 (2015), various features of the coastal and city hotels are also used for making some determinations and inferences under the study.

A model that resembles the model created by Turunç and Avc1 (2015) was constructed pursuant to the study; however, instead of the organizational support and the quality of the leader-member interaction variables, the research model involved supervisor support variable, which is closely related to aforementioned concepts. Furthermore, the study was conducted on the employees at the city hotels on the basis of the study's suggestion conducted on those at the coastal hotels by Turunç and Avc1 (2015).

It is possible to state that the present study predicates on the Conservation of Resources Theory (Hobfoll, 1989) and the Social Exchange The- 
ory (Blau, 1964). Based on the Conservation of Resources Theory, the conviction of the individual, who contemplate that they are valued by their supervisors, that their wellbeing and contentment is considered important, that they have some remedy as the supervisor support and that they have access to such remedy when experiencing some troubles at the workplace environment might be able to diminish the negative impact of the stressors at the workplace. Similarly, in the light of the Social Exchange Theory, the employees are expected to experience less work stress and to alienate from the intention to quit in return for the support from their supervisors.

The supervisor support relates to the support, attention, stimulation and encouragement offered to the employees by their superiors (Babin and Boles, 1996, p. 60). The literature proves that the employees perceiving higher support experience less work stress (e.g.: Bardakoğlu et al., 2017; Wickramasinghe, 2012) and alienate from the intention to quit (e.g.: Afacan Findıklı, 2014; Dysvik and Kuvaas, 2013; Kalidass and Bahran, 2015; Newman, Thanacoody and Hui, 2012; Nichols, Swanberg and Bright, 2016). The work stress can be defined as "the psychological reaction of the individual towards any situation that exceeds his/her capacity or resources" (LePine et al., 2004, p.883). The intention to quit, which leads to adverse outcomes not only in the psychological sense, but also in the sociologic and economic sense, can be expressed as the desire and plan of the employee to leave the organization (Timinepere et al., 2018, p. 150). The studies available at the literature (Akova, Emiroglu and Tanriverdi, 2015; Arshadi and Damiri, 2013; Noor and Maad, 2008; Qureshi et al., 2013; Savaş and Erol, 2017; Sewwandi and Perere, 2016) statistically demonstrate that the work stress is a positive predictor of the intention to quit.

\section{Method}

\section{Research Model and Hypothesis}

Based on the theoretical information and empirical studies available in the literature, the research model of the study (see Appendix 1) has been established and the hypothesis has been developed. 
Hypothesis: The work stress of the employees plays a mediating role in the relationship between the perceived supervisor support and the employees' intention to quit.

\section{Sample and Materials}

Questionnaires were distributed to 684 individuals employed at 33 city hotels in total, 17 in Adana and 16 in Ankara, through convenience sampling method; but only 512 individuals responded back. The rate of return is approx. $75 \%$. Only 395 questionnaires from total of 512 questionnaires proved to be eligible for the study. The size of the dataset of the study has become definite as 395 questionnaires after completion of the preliminary analyses through the method suggested by Tabachnick and Fidell (2013). The 11-item scale, developed by Giray and Şahin (2012), was used for measuring the perceived supervisor support. The 7-item scale, developed by House and Rizzo (1972) and adapted to the Turkish by Efeoğlu (2006), was used for measuring the work stress. The 3-item scale, developed by Wayne, Shore and Liden (1997) and adapted to the Turkish by Küçükusta (2007), was used for measuring the intention to quit. The responses at these scales were given on five-point Likert scale. The questionnaire form also contains demographic questions.

\section{Procedure and Analysis Approach}

The method of questionnaire was employed for acquisition of data in this study, where quantitative research was performed. First of all, the data was inputted to digital format using the "SPSS 24" software. "SPSS 24" software was used to identify the demographics of the participants to the study after completing preliminary analyses of the dataset, to test the construct validity of the research model through exploratory factor analysis, to compute the mean and standard deviation values of the variables in the research model, and to employ the reliability, Pearson correlation and regression analyses. Finally, the Sobel test was performed in the interactive media. 


\section{Results and Discussion}

$35.4 \%$ of the employees taking part in the study are women, and $64.6 \%$ are men. These ratios indicate that there are much more men than the women. When we look further into the demographics of the employees, we see that the largest ratios of participants are for the age interval 30-39 (36.7\%), for high school graduates (47.8\%), and for working for less than 1 year (35.7\%).

All items of three distinct variables in the research model were subjected to overall exploratory factor analysis using SPSS 24 software. The lowest factor load has been determined as ".54" under the study, which is an acceptable value (Hair et al., 2010). The lowest value of Cronbach's alpha reliability coefficient for the variables addressed under the study is calculated to be ". 81 ". The fact that this value is higher than the value recommended by Hair et al. (2010), i.e., ".70", indicates that all scales used under the study are reliable.

The results of the correlation analysis have revealed that there is a significant and negative relation between the perceived supervisor support and employees' work stress $\quad(\mathrm{r}=-.31 ; \mathrm{p}<.01)$, that there is a significant and negative relation between the perceived supervisor support and the employees' intention to quit $(\mathrm{r}=-.32 ; \mathrm{p}<.01)$, that there is a significant and positive relation between employees' work stress and intention to quit ( $\mathrm{r}=$ $.45 ; \mathrm{p}<.01)$ in line with the theoretical and empirical studies available in the literature.

The method proposed by Baron and Kenny (1986) was pursued at the hierarchical regression analysis performed for testing the research hypothesis of the study. According to analysis results seen in Appendix 1, the perceived supervisor support has a negative and significant effect on the employees' intention to quit $(\beta=-.324 ; \mathrm{p}<.01)$. Therefore; the first condition concerning mediation is hereby fulfilled. Furthermore, the perceived supervisor support has a negative and significant effect on employees' work stress $(\beta=-.312 ; p<.01)$, while the work stress of the employees has a positive and significant effect on their intention to quit $(\beta=.397$; $\mathrm{p}<.01)$. Therefore, the second and the third conditions concerning mediation are also hereby fulfilled. When the work stress is included into the regression equation, the perceived supervisor support continues to affect 
the employees' intention to quit in a negative and significant manner with reduced effect $(\beta=-.200 p<.01)$. In this case; the fourth condition concerning mediation is also hereby fulfilled. After fulfillment of all four conditions concerning mediation, finally the Sobel test was conducted in the interactive medium. At the end of the Sobel test (Preacher and Leonardelli, 2010); it is determined that the mediating effect of the work stress in the relationship between the perceived supervisor support and employees' intention to quit is statistically significant $(Z=-5.22 ; p<.001)$. Therefore, the research hypothesis is accepted. Furthermore, in this mechanism, the work stress variable plays a partially mediating role. Therefore; it is possible to reduce the level of employees' intention to quit both directly and indirectly through a drop in the work stress level of these employees thanks to the increase in perceived supervisor support level. In the light of all this information; it is concluded that it is possible to decrease the damaging effects of work stress and intention to quit on the organization and thus to contribute to it by reducing the levels of aforementioned variables through the increase in the level of perceived supervisor support.

The results obtained under the scope of the study present similarities with the results from the study by Turunç and Avc1 (2015). It is contemplated that the stress factor has an impact on obtainment of such similar results. However, it is possible to mention that, due to the differences between the founding purposes, functioning and customer profiles of city and coastal hotel types, the sources of stress, i.e. the stressors, of the employees dissociate at respective hotels. Based on the differences between the founding purposes, functioning and customer profiles of the coastal and city hotel types and various observations, it is possible to make various deductions on what the sources of stress encountered at the respective hotel types can be. The coastal hotels are extremely crowded especially during the tourism season. Such over crowdedness increase the work load of the employees and raise their stress levels. Moreover, a significant portion of the employees at such hotels become unemployed outside the tourism season. The employees' concern for losing their employment in the future might elevate their stress levels. On the other hand, as the customer profile of the city hotels represents more elite tier when compared to the coastal hotels, it is possible to anticipate that the expectation of the city hotel customers concerning the quality and continuity of delivered service 
would be higher when compared to the coastal hotel customers. It is also possible to mention that the city hotels feature a customer profile formed by same persons and that such persons accommodate at such hotels for short periods. Satisfaction of such short-term staying customers during the period of stay is important to ensure return of such customers to the hotel. The expectation of such persons, who desire to achieve the comfort of their homes at the hotel, on achievement and maintenance of the high levels of quality standard might stress the employees of the city hotels due to fear of complaints to the hotel administration by the guests, fear of criticism by their supervisors and even fear of dismissal. At this point; the attitudes and behaviors of the supervisor with respect to identification and elimination of the respective stressors are of vital importance for achievement of the organizational success, that is to say organizational effectiveness and efficiency. The support offered by the supervisor to the employees for the sake of fulfilling the customer expectations shall contribute to achievement of the organizational success. In case the supervisor support proves to be insufficient, then the stress level of the employees, and accordingly, their level of intention to quit shall rise. Realization of the intention to quit might present a major problem for any enterprise aiming high standards and continuity with respect to quality. Because selection, placement and orientation of another person with adequate qualifications as replacement of the quitting employee shall require time. This might lead to lower organizational effectiveness and efficiency especially at the city hotels.

Further studies might be conducted to obtain more detailed outcomes on the research variables and the relationships between such variables by implementing qualitative data analysis through data collection methods such as interviews, observations, etc. Furthermore, the model can be expanded by adding other variables such as personality (psychological endurance, type A and B personality) and demographic characteristics of employees, trust and job security to the model. 
Appendix 1 - The Summary of Regression Analysis Results (The Research Model of the Study)

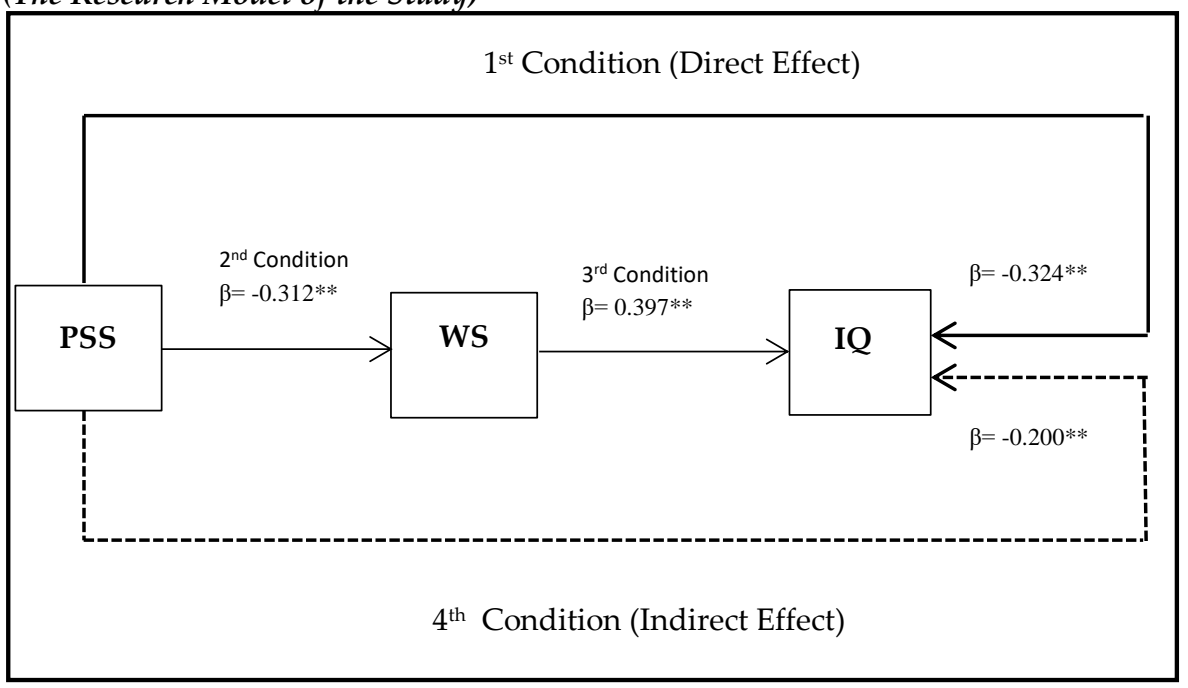

Notes: ${ }^{* *} p<0.01 ; \beta=$ Standardized regression coefficient; Abbreviations: PSS: Perceived Supervisor Support; WS: Work Stress; IQ: Intention to Quit

\section{Kaynakça / References}

Afacan Fındıklı, M. (2014). Algılanan lider desteği ve algılanan örgütsel destek ile işten ayrılma niyeti ilişkisinde örgütsel özdeşlemenin aracılık rolü: İstanbul'da kamu çalışanları üzerine bir araştırma. İ.Ü. İşletme Fakültesi Işsletme İktisadi Enstitüsü Yönetim Dergisi, 25 (77), 136-157.

Akova, O., Emiroglu, B. D. ve Tanriverdi, H.(2015). Satisfaction and turnover intent: A study at Five star Hotels in İstanbul. Journal of Management, Marketing and Logistics, 2 (4), 378- 402.

Arshadi,N. ve Damiri, H. (2013). The relationship of job stress with turnover intention and job performance: Moderating role of OBSE. Social and Behavioral Sciences, 84, 706-710.

Aydın, İ. (2016). İş yaşamında stres (4. bs.). Ankara: Pegem Akademi Yayınları.

Azman, I., Sieng, L.L.C., Ajis, M.N., Dollah, N.F. ve Boerhannoeddin, A. (2009). Relationship between supervisor's role and job performance in the workplace training program, 237-251. 
Babin, B. J. ve Boles, J.S. (1996). The effects of perceived co-worker involvement and supervisor support on service provider role stress, perfrmance and job satisfaction. Journal of Retailing, 72(1), 57-75.

Bardakoğlu, Ö., Akgündüz, Y., Kızılcalığlu, G. ve Yeşilyurt, H. (2017). Otel işletmelerinde algılanan yönetici desteğinin çalışanların iş stresi ve mutluluk düzeylerine etkisi. 8.Uluslararası Girişimcilik Kongresi, 103-116.

Baron, R. M. ve Kenny, D. A. (1986). The Moderator-Mediator Variable Distinction Social Psychological Research: Conceptual, Stategic and Statistical Considerations. Journal of Personality and Social Psychology, 51(6), 1173-1182.

Bhanthumnavin, D. (2000). Importance of supervisory social support and its implications for HRD in Thailand. Psychology and Developing Societies, 12(2), 155-166.

Bhanthumnavin, D. (2003). Perceived social support from supervisor and group members' psychological and situational characteristics as predictors of subordinate performance in Thai work units. Human Resource Development Quarterly, 14(1), 79-97.

Bhatti, M. H., Bhatti, M. H., Akram, M. U., Hashim, M. ve Akram, Z. (2016). Relationship between job stress and organizational commitment: An empirical study of banking sector. Journal of Business Management and Economics, 7(1), 29-37.

Bilici, A. (2009). Konaklama işletmelerinde stres yönetimi ve Konya örneği. Yayımlanmamış Yüksek Lisans Tezi, Selçuk Üniversitesi, Konya.

Blau, P. M. (1964). Exchange and power in social life. New York: John Wiley \& Sons, Inc: USA.

Chiang, F.F.T., Birtch, T.A. ve Kwan, H.K. (2010). The moderating roles of job control and work-life balance practices on employee stress in the hotel and catering industry. International Journal of Hospitality Management, 29, 25-32.

Cummins, R. C. (1990). Job stress and the buffering effect of supervisory support. Group \& Organization Studies, 15(1), 92-104.

Çalışkan, S.C. (2009). Turizm işletmelerinde liderlik tarzları ve lider-üye etkileşimi kalitesi (LÜE) üzerine bir çalışma. Trakya Üniversitesi Sosyal Bilimler Dergisi, 11(2), 219- 241. 
Dysvik, A. ve Kuvaas, B. (2013). Perceived job autonomy and turnover intention: The moderating role of perceived supervisor support. European Journal of Work and Organizational Psychology, 22(5), 563-573.

Efeoğlu, İ. E. (2006). İş-aile yaşam çatışmasının iş stresi, iş doyumu ve örgütsel bağlllık üzerindeki etkileri: İlaç sektöründe bir araştırma. Yayınlanmamış Doktora Tezi, Çukurova Üniversitesi, Adana.

Eroğlu, F. (2015). Davranış bilimleri (14. bs.). İstanbul: Beta Yayınları.

Fong, Y. L. ve Mahfar, M. (2013). Relationship between occupational stress and turnover intention among employees in a furniture manufacturing company in Selangor. Journal Teknologi (Social Sciences), 64(1), 33-39.

Gillespie, N. A., Walsh, M., Winefield, A. H., Dua, J. ve Stough, C. (2001). Occupational stress in universities: staff perceptions of the causes, consequences and moderators of stress. Work \& Stress, 15(1),53-72.

Giray, M. D. ve Şahin, D. N. (2012). Algılanan örgütsel, yönetici ve çalışma arkadaşları desteği ölçekleri: Geçerlik ve güvenirlik çalışması. Türk Psikoloji Yazıları, 15(30), 1-9.

Gouldner, A. W. (1960). The norm of reciprocity: A preliminary statement. American Sociological Review, 25, 161-178.

Hair, J.F., Black, W.C., Babin, B.J. ve Anderson, R.E. (2010). Multivariate data analysis (7. Bask1). NJ: Pearson Prentice Hall, Upper Saddle River.

Hobfoll, S.E. (1989). Conservation of resources: A new attempt at conceptualizing stres. American Psychologist, 44(3), 513-524.

House, R.J. ve Rizzo, J. R. (1972). Role conflict and ambiguity as critical variables in model of organizational behavior. Organizational Behavior and Human Performance, 7(3), 467-505.

Hutchison, S. (1997). A path model of perceived organizational support. Journal of Social Behavior and Personality, 12 (1), 159- 174.

Irawanto, D. W. ve Noermiyati, Primasari, D. (2015). The effect of occupational stress on work performance of female employees: Study in Indonesia. Asia-Pacific Journal of Management Research and Innovation, 11 (4), 336-345.

Kalaycı, Ş. (2010). SPSS uygulamal çok değişkenli istatistik teknikleri. Ankara: Asil Yayınevi.

Kalemci Tuzun, İ. ve Kalemci, A. (2012). Organizational and supervisory support in relation to employee turnover intentions. Journal of Managerial Psychology, 27(5), 518-534. 
Kalidass, A. ve Bahron, A. (2015). The relationship between perceived supervisor support, perceived organizational support, organizational commitment and employee turnover intention. Interntional Journal of Business Administration, 6(5), 82-89.

Khalid, A., Rathore, K. ve Aslam, N. (2017). The influence of supervisory support on work motivation: A moderating role of organizational support. New Trends and Issues Proceedings on Humanities and Social Sciences, 4(10), 136-143.

Khattak, J.K., Khan, M.A., Haq, A.U., Arif, M. ve Minhas, A. A. (2011). Occupational stress and burnout in Pakistan's banking sector. African Journal of Business Management, 5(3), 810-817.

Küçükusta, D. (2007). Konaklama işletmelerinde iş-yaşam dengesinin çalışma yaşamı kalitesi üzerindeki etkisi. Yayınlanmamış Doktora Tezi, Dokuz Eylül Üniversitesi, İzmir.

LePine, J.A., LePine, M.A. ve Jackson, C.L. (2004). Challenge and Hindrance Stress: Relationships with exhaustion, motivation to learn and learning performance. Journal of Applied Psychology, 89(5), 883-891.

Naidoo, R. (2018). Role stress and turnover intentions among information technology personnel in South Africa: The role of supervisor support. SA Journal of Human Resource Management, 16(1), 1-10.

Newman, A., Thanacoody, R. ve Hui, W. (2012). The effects of perceived organizational support, perceived supervisor support and intra-organizational network resources on turnover intentions. Personnel Review, 41(1), 56-72.

Nichols, H.M., Swanberg, J. E. ve Bright, C.L. (2016). How does supervisor support influence turnover intent among frontline hospital workers? The mediating role of affective commitment. The Health Care Manager, 35(3), 266-279.

Noor, S. ve Maad, N. (2008). Examining the relationship between work-life conflict, stress and turnover intentions among marketing executives in Pakistan. International Journal of Business and Management, 3(11), 93102.

O'Neill, J. W. ve Davis, K. (2011). Work stress and Well-being in the Hotel Industry. International Journal of Hospitality Management, 30(2), 385-390.

Oral, S. ve Kurgun, O.A. (1997). Otel işletmeciliği ve otel işletmelerinde verimlilik analizleri. Kanyılmaz Matbaası, İzmir, Türkiye. 
Özdemir, S. ve Özdemir, Y. (2015). İşten ayrılma niyeti ve işten ayrılma niyeti ile ilgili akademik çalışmaların incelenmesi. R.Ö.Kutanis (Ed.), Türkiye'de Örgütsel Davranış Çalışmları I içinde (s.335-356). Ankara: Gazi Kitabevi.

Özkara, Z. U., Taş, A. ve Aydıntan, B. (2019). Algılanan yönetici desteği ile örgütsel sinizm arasındaki ilişkide lider-üye etkileşiminin aracılık etkisi. OPUS-Uluslararası Toplum Araştırmaları Dergisi, 12(18. UİK Özel Sayısı), 101-137.

Pohl, S. ve Galletta, M. (2016). The role of supervisor emotional support on individual job satisfaction: A multilevel analysis. Applied Nursing Research, 33, 61-66.

Preacher, K.J. ve Leonardelli, G.J. (2010). Calculation for the sobel test: an interactive calculation tool for mediation tests. Erişim Tarihi: 07.12.2019, url: http://www.quantpsy.org/sobel/sobel.htm.

Qureshi, M. A. ve Hamid, K.(2017). Impact of supervisor support on job satisfaction: A Moderating role of fairness perception. International Journal of Academic Research in Business and Social Sciences, 7 (3), 235-242.

Qureshi, M. I., Iftikhar, M., Abbas, S. G., Hassan, U., Khan, K. ve Zaman, K. (2013). Relationship between job stress, workload, environment and employees turnover intentions: what we know, what should we know. World applied Sciences Journal, 23(6),764-770.

Rhoades, L. ve Eisenberger, R. (2002). Perceived organizational support: A review of the literature. Journal of Applied Psychology, 87(4), 698-714.

Ross, R.R. ve Altmaier, E. M. (1994). Intervention in Occupational Stress, London, SAGE Publications.

Rusbult, C. E., Farrell, D., Rogers, G. ve Mainous, A.G. (1988). Impact of exchange variables on exit,voice, loyalty, and neglect: An Integrative model of responses to declining job satisfaction. Academy of Management Journal, 31(3), 599-627.

Salahian, A., Oreizi, H.R., Abedi, M.R. ve Soltani, I. (2012). Co-workers /Supervisor support and burnout. Interdisciplinary Journal of Contemporary Research in Business, 4(1), 141-148.

Saunders, M., Lewis, P. ve Thornhill, A. (2009). Research Methods for Business Students (5. bs.). Prentice Hall.

Savaş, A. C. ve Erol, F. (2017). Eğitim personellerinde iş stresinin işten ayrılma niyetine etkisinde depresyon düzeylerinin aracılık etkisi. Yaşam Becerileri Psikoloji Dergisi, 1(2), 115-123. 
Settoon, R. P., Bennett, N. ve Liden, R. C. (1996). Social exchange in organizations: Perceived organizational support, leader-member exchange, and employee reciprocity. Journal of Applied Psychology, 81(3), 219- 227.

Sewwandi, D. V. S. ve Perere, G.D.N. (2016). The impact of job stress on turnover intention: A study of reputed apparel firm in Sri Lanka. 3rd International HRM Conference, 3(1), 223-229.

Tabachnick, B.G. ve Fidell, L.S. (2013). Using multivariate statistics (6. Bask1), Boston: Allyn \& Bacon.

Tett, R. P. ve Meyer, J. P. (1993). Job satisfaction, organizational commitment, turnover intention, and turnover: Path Analyses based on meta-analytic findings. Personnel Psychology, 46, 259-293.

Timinepere, C.O., Agbaeze, E. K., Ogbo, A. ve Uche, N. C. (2018). Organizational Justice and Turnover Intention Among Medical and Non-Medical Workers in University Teaching Hospitals. Mediterranean Journal of Social Sciences, 9(2), 149-160.

Turunç, Ö. ve Avcl, U. (2015). Algılanan örgütsel destek ve lider-üye etkileşiminin işten ayrılma niyeti üzerindeki etkisi: İşs stresinin aracılık rolü. Seyahat ve Otel İşletmeciliği Dergisi, 12(1), 43- 63.

Vasse, R. M., Nijhuis, F. J.N. ve Kok, G.(1998). Associations between work stress, alcohol consuption and sickness absence. Addiction, 93(2), 231-241.

Wang, Z. (2014). Perceived supervisor support and organizational citizenship behavior: The role of organizational commitment. International Journal of Business and Social Science, 5(1), 210- 214.

Wayne, S.J., Shore, L.M. ve Liden, R.C. (1997) . Perceived organizational support and leader-member exchange: A social exchange perspective. Academy of Management Journal, 40(1), 82-111.

Wickramasinghe, V. (2012). Supervisor support as a moderator between work schedule flexibility and job stress. International Journal of Workplace Health Management, 5(1), 44-55.

Yang, T., Shen, Y. M., Zhu, M., Liu, Y., Deng, J., Chen, Q. ve See, L. C.(2016). Effects of co-worker and supervisor support on job stress and presenteeism in an aging workforce: A Structural Equation Modelling Approach. International Journal of Environmental Research and Public Health, 13(72), 1-15.

Yoon, J. ve Lim, J. C. (1999). Organizational support in the workplace: The case of Korean hospital employees. Human Relations, 52(7), 923- 945. 
Yüksel, İ. (2006). Örgütsel destek algıSı ve belirleyicilerinin işten ayrılma eğilimi ile ilişkisi. İşletme Fakültesi Dergisi, 35(1), 7-32.

\section{Kaynakça Bilgisi / Citation Information}

Taş, A. ve Özkara, Z. U. (2020). İş stresinin algılanan yönetici desteği ile işten ayrılma niyeti arasındaki ilişkide üstlendiği rol. OPUSUluslararası Toplum Araştırmaları Dergisi, 15(21), 475-504. DOI: 10.26466/opus.662681 